\title{
Maternal Tasks of the Puerperium Reidentified
}

\author{
Lynette A. Ament \\ Loyola University Chicago
}

Follow this and additional works at: https://ecommons.luc.edu/luc_theses

Part of the Medicine and Health Sciences Commons

\section{Recommended Citation}

Ament, Lynette A., "Maternal Tasks of the Puerperium Reidentified" (1986). Master's Theses. 3443.

https://ecommons.luc.edu/luc_theses/3443

This Thesis is brought to you for free and open access by the Theses and Dissertations at Loyola eCommons. It has been accepted for inclusion in Master's Theses by an authorized administrator of Loyola eCommons. For more information, please contact ecommons@luc.edu. c) (i) (9)

This work is licensed under a Creative Commons Attribution-Noncommercial-No Derivative Works 3.0 License. Copyright (C) 1986 Lynette A. Ament 


\title{
MATERNAL TASKS OF THE \\ PUERPERIUM REIDENTIFIED
}

\section{by}

\author{
Lynette A. Ament
}

A Thesis Submitted to the Faculty of the Graduate School of Loyola University of Chicago in Partial Fulfillment of the Requirements for the Degree of Master of Science in Nursing

December

1986 


\section{ACKNOWLEDGMENTS}

I wish to thank the director of this thesis committee, Dr. Karen Haller, for her guidance and leadership in completion of this project. I also wish to thank the committee members, Dr. Dona Snyder and Ms. Marcia Maurer, for their guidance and suggestions.

Special thanks goes to Lake Forest Hospital for the use of their facilities to perform and complete this research. I am grateful to Anita Davellis and the entire obstetrical staff for their cooperation in administering questionnaires to the participants. 
VITA

The author, Lynette Anne Ament, is the daughter of Charles and Esther (Slavin) Hamlin. She was born March 22, 1960 in Waukegan, Illinois.

Her elementary education was obtained at St. Peter school in Antioch, Illinois. Her secondary education was completed in 1978 at Antioch Community High School, Antioch, Illinois.

Ms. Ament attended Southern Illinois University from 1978 to 1980. During this time she was a President's Scholar and received a Certificate of Merit in Mathematics. She received the degree of Bachelor of Science in Nursing from Loyola University of Chicago in June, 1982.

Ms. Ament is a member of the American Nurses Association and the Nurses Association of the American College of Obstetricians and Gynecologists. Publications include Supportive Care and Feeding Ability of the Premature Infant, CHART, $\underline{82}(8), 1985$. 
Page

ACKNOWLEDGMENTS............................... ii

$\operatorname{VITA} \ldots \ldots \ldots \ldots \ldots \ldots \ldots \ldots \ldots \ldots \ldots \ldots \ldots \ldots \ldots \ldots \ldots \ldots \ldots \ldots \ldots$

LIST OF TABLES.............................. v

LIST OF ILLUSTRATIONS......................... vi CONTENTS OF APPENDICES........................ vii Chapter

I. INTRODUCTION........................... 1

II. REVIEW OF LITERATURE..................... 5

III. METHOD............................... 12

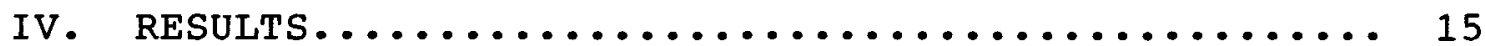

V. DISCUSSION............................ 26

REFERENCES................................... 30

APPENDIX A................................. 31

APPENDIX B................................. 35 


\section{LIST OF TABLES}

Table

1. Results of Repeated Measures ANOVA for all

Participants........................... 17

2. Results of Repeated Measures ANOVA by Parity..... 20

3. Results of Repeated Measures ANOVA by Age....... 21 


\section{LIST OF ILLUSTRATIONS}

Figure

1. "Taking-in" scores in relation to "taking-hold" scores over time......................... 18

2. "Taking-in" scores by age groups over time...... 22

3. "Taking-hold" scores by age groups over time.... 23

4. "Taking-in" scores by parity over time......... 24

5. "Taking-hold" scores by parity over time....... 25 
CONTENTS OF APPENDICES

Appendix A

I. Duration and Behaviors of Concepts.......... 32

II. Postpartum Questionnaire............... 33

III. Demographic Data..................... 34

Appendix B

I. Informed Consent.................... 36 
CHAPTER I

INTRODUCTION

Reva Rubin (1961) introduces her article "Puerperal Change" by stating "the woman in her immediate postpartum period undergoes phenomenal physical and psychological changes to which greater attention could well be given" (p. 753). The physical aspects of the postpartum mother follow a usual routine. It is here that a nurse performs "routine tasks". Both psychic and physical energies of the parturient must be considered in providing nursing care. Rubin states that with better understanding of these aspects, nurses can foster the new mother's development of the maternal role to the fullest extent of her capacities.

Rubin describes two phases of maternal tasks that are reflected in observable behaviors and attitudes. The goal of these tasks is to restore interpersonal skills and establish mothering behaviors. Restoration is exhibited by the "taking-in" phase (passive and dependent maternal behavior) and by the "taking-hold" phase (independent and autonomous maternal behavior). The "taking-in" phase lasts for two to three days. The parturient (new mother) needs to 
review and comprehend the details of her labor during this phase. She receives care and initiates very little. The "taking-hold" phase begins during the parturient's third day. She now becomes involved in her own care. Anxiety occurs as she hurries to become autonomous again. This phase will last approximately ten days, before the process of regeneration is complete.

Rubin's concept of puerperal change is concerned with postpartum mothers who are undergoing a process of change, regardless of any nursing intervention. Nursing literature and personal experience indicate nurses have chosen to accept Rubin's framework and develop nursing care plans based on her assumptions. Current maternity textbooks use Rubin's "puerperal change" as the theoretical framework for postpartal nursing care (Clausen, Flook, \& Ford, 1977; Reeder, Mastroianni, \& Martin, 1980; Ziegel, \& VanBlarcom, 1972). Yet no empirical studies have validated Rubin's framework. When applied literally to current practice, is it or is it not still applicable?

\section{DEFINITION OF TERMS}

\section{$\underline{\text { Key terms }}$}

1. Puerperium: The period elapsing between the termination of labor and the return of the uterus to its normal condition, about six weeks. 
2. Maternal tasks: Restoration of interpersonal and production skills as exhibited by

a. "taking-in" phase: passive and dependent maternal behavior

b. "taking-hold" phase: independent and autonomous maternal behavior

\section{Key Definitions}

Following are the operational definitions as defined by Martell \& Mitchell, 1984.

1. Taking-in (first three days)

a. energy level: sleep needed, fatigued

b. time orientation: past, talks about labor

c. interpersonal interests: self-focused, talkative to others about labor

d. dependent, accepting, wants others to meet needs, compliant, needs direction

e. focus of energy: food, baby's intake

f. mood and affect: passive, euphoric

2. Taking-hold (three to ten days)

a. energy level: active, may be sleepy, hungry

b. time orientation: present

c. interpersonal interests: others and self, baby, family 
d. independent, initiates activities, tends to organize

e. focus of energy: mothering tasks, regaining bodily functions

f. mood and affect: active, tends to be anxious, subject to mood swings that stabilize with time, impatient

SPECIFIC QUESTIONS AND ASSUMPTIONS

\section{Questions}

A descriptive study of women receiving hospital postpartal care was undertaken to answer two questions:

1. Do the subjects show "taking-in" and "taking-hold" behaviors and attitudes as described by Rubin?

2. Do these behaviors and attitudes change over time during the course of hospitalization?

\section{Assumptions}

The following assumptions were accepted in the proposed study :

1. The state of the new mother's physical and physic energy is reflected in observable behaviors and attitudes.

2. The behaviors and attitudes change systematically in two stages during the postpartal period. 


\section{REVIEW OF LITERATURE}

Conflict exists between nursing concepts and current nursing practice for the postpartum patient. Nurses provide care to clients based on both theoretical knowledge and knowledge gained through personal experience.

Theoretically, each should coincide with the other. In practice, though, this is not necessarily so. Discrepancies are arising and the validity of some concepts are being questioned. One such concept under question is that of Rubin's "puerperal change".

A number of maternity nursing texts stress the importance of basing nursing practice on the completion of Rubin's maternal tasks (Clausen, Flook, \& Ford, 1977; Reeder, Mastroianni, \& Martin, 1980; Ziegel, \& VanBlarcom, 1972). Reeder et al. state that the nurse should be especially cognizant of the mother's need for added nourishment, and moreover, should be aware that a poor appetite is a symptom that the "taking-in" phase is not proceeding normally. The authors emphasize that during the "taking-hold" phase the nurse should not intervene during mother-baby interactions, thus promoting independence. 
Nursing researchers and practitioners have proceeded on the assumption that Rubin's framework is valid. Bull (1981) suggests a maternal focus on self and infant from the third day postpartum continuing through one week at home. Maternal concerns shift from self to infant once her needs have been met. Mercer (1981) describes nursing interventions that allow the postpartal nurse to play a vital role in helping the woman resolve her feelings towards the achievement of her tasks. For example, Mercer states it is important for the labor nurse to review the labor with the woman to assist the woman in integrating the birth experience. "Hence, one of the goals for maternity nursing is achieved" (Mercer, 1981).

As a result of the vast majority of women attending childbirth education, consumer attitudes and beliefs may be changing. The majority of such programs now include information on the postpartum period (Sasmor \& Grossman, 1981). Many childbirth educators assume that women are now more prepared for the tasks of motherhood, but there is no data to support this assumption.

One variable that may influence task achievement is the practice of early postpartum hospital discharge, in which mother and infant are discharged within twenty-four hours of delivery. If these women are in the dependent, "taking-in" state, how do they accomplish the postpartal 
transitions without the assistance of the postpartal nurse? In some instances, nurses may make home visits only once per day for two days after early discharge (Avery \& Fournier, 1982; Carr \& Walton, 1982); often even this does not occur. According to Jones (1978), antepartal preparation is related to the patient's rapid recovery. She states that the success of early discharge depends largely on the mother's confidence in her ability to cope with the new baby, and that a good memory of the delivery experience apparently is related to the patient's rapid recovery. There is little research substantiating the inference that these women successfully complete their maternal tasks at a faster pace than defined by Rubin.

Rubin first developed the concept of puerperal change in her 1961 work. She defines the period of the puerperium and identifies the adaptive, physiological changes of the postpartum mother. Rubin (1961) then relates the physiological changes to concurrent psychological changes, thus the concept "puerperal change". It is here that she introduces "taking-in" and "taking-hold" stages; they are defined in terms of duration and identifiable behaviors (see Appendix A). She concludes by stating that with a better understanding of these tasks, nurses can more fully appreciate the significance of this time period. 
Inherent in this discussion is the reliability of Rubin's original research (1967). Rubin's theory is based on data she collected and compiled between 1960 and the early 1980 's. In the 1967 study the problem studied was how a particular adult role is acquired, specifically the maternal role. The research question was: "What are the processes involved in the acquisition of maternal role?" (p. 238).

The method used was unstructured interviews and observations to permit freedom of subject expression and association (Rubin, 1967). Five primiparas and four multiparas were studied in depth. To control for experimentor effects, additional subjects were obtained for one or two interviews each. The observer-interviewers were graduate nurses. The number of nurses involved was not discussed.

Final data were analyzed on the basis of 15 subjects, and were scored using 4,799 relevant items (Rubin, 1967). By the ninth postpartum day, data were based on only 7 of the original 15 subjects. The nurse observers recorded their observations and Rubin completed the scoring. This was done to effect a double-blind study. It is also not clear here how Rubin tested the two concepts in question ("taking-in" and "taking-hold"). 
Many items are missing in the discussion, which leaves questions unanswered. For example, had the observers been sufficiently trained to use the observational methods? Did observers make undue inferences? No interrater reliability was done. The selection procedure for subjects was also not specified.

Rubin (1967) also failed to include a discussion of the limitations of qualitative analysis. The relative absence of quantification makes it difficult to present conclusions in such a way as to convince others of their validity (Polit and Hungler, 1983). This also makes it more difficult to replicate the results. Qualitative methods tend to yield vast amounts of data from small samples that are generally selected at random, thus the generalizability of the conclusions is often questionable (Polit and Hungler, 1983).

Qualitative analysis is useful for preliminary theory building in an area that has not previously been researched. But in the case of Rubin's work, nursing has overgeneralized and made this a major basis for postpartal care. According to Haller (1979), to avoid the possibility of implementing an innovation based on a "false positive", an effort should be made to establish that the conceptual and constructive propositions have been confirmed in more than one study 
(p. 47). Replication of Rubin's study and its results have been very difficult (Martell \& Mitchell, 1984).

Rubin (1984) no longer discusses the puerperium in such definitive terms. Rather, she discusses the taking-in phase of the postpartum period as a subjective maternal experience that occurs during the first three weeks after delivery. A taking-hold phase is never mentioned. It seems Rubin has modified her ideas. If this be so, it seems timely to reevaluate and even redefine the importance of the concepts in question.

Martell \& Mitchell (1984) attempted to replicate Rubin's (1960) observations. In their study the problem investigated was whether healthy new mothers exibited Rubin's "taking-in" and "taking-hold" behaviors and attitudes and if these behaviors and attitudes changed during the course of hospitalization. Twenty subjects, randomly selected, were administered a questionnaire on each morning of hospitalization. The length of hospitalization varied between two and three days.

The questionnaire format used consisted of 22 items designed by Martell \& Mitchell (1984), 13 items reflecting "taking-in" and 9 items reflecting "taking-hold". The questionnaire had never been used before. Content validity was established using a panel of five maternity nursing educators. Martell \& Mitchell found little evidence to 
suggest a strong "taking-in" pattern, but there was evidence for a "taking-hold" pattern.

Some questions can be raised about the instrument used by Martell \& Mitchell (1984). Construct validity and reliability were not reported. It is not reasonable to assume that a greater degree of objectivity can be obtained in a patient's report of her own behavior than by an observer (Maloni, 1984). Concurrent validity could have been established utilizing a nurse-observer to validate the reported behaviors with observed behaviors. Then the argument for construct validity would have been strengthened.

Another problem to be considered is the administration of the questionnaire. Martell \& Mitchell (1984) administered it to each subject each morning of hospitalization for a maximum of three consecutive days. The first questionnaire was given no earlier than eight hours postpartum, thus it fails to take into account the possibility of the maternal tasks occurring faster and/or sooner than Martell \& Mitchell had anticipated. Further research is needed to redress the threats to validity in Martell \& Mitchell's study and to replicate the findings. 


\section{METHODOLOGY}

The completed research was nonexperimental. It was a descriptive study using a repeated measures design. The target population was postpartal women with uncomplicated vaginal deliveries, while the accessible population was postpartal women who delivered at a suburban Chicago hospital. No attempt was made to select subjects according to gravidity, parity, socioeconomic status, age, ethnicity, or marital status, since Rubin (1967) and Martell \& Mitchell (1984) made no such exclusions. A convenience sample was selected from clients who delivered between the hours of 0600 and 1300. The sample consisted of fifty women.

The instrument used was an adaptation of the questionnaire designed by Martell \& Mitchell (1984). Their questionnaire consisted of 22 statements: 13 reflecting the "taking-in" concept, 9 reflecting the "taking-hold" concept (see Appendix A). It was a closed-ended format that required an agree or disagree statement. Each question received one point for an agree answer. Martell \& Mitchell established content validity through the use of an expert panel; agreement between panel members was 918. For this study Martell \& Mitchell's response options were altered 
from agree/disagree to a Likert-type rating scale, ranging from 1 to 4 (strongly agree, agree, disagree, and strongly disagree) to strengthen the psychometric properties of the scale.

The self-administered questionnaire was given to the woman one hour after leaving the delivery room, then two hours later, then at 2200 that evening, and on each morning of hospitalization for two days. Subjects were instructed to take their time and leave it at the bedside.

The study hospital averages 140 vaginal and cesarean deliveries per month. By three hours postpartum, the typical patient at this hospital is ambulatory. Postpartal patients stay an average of 72 hours. Early discharge is a rare occurrence, and patients discharged early were not included in this study.

The data were collected between July 23, 1985 and October 13, 1985. There was one refusal. The population was largely middle class. Age ranged from 17 to 38 years, with the median being 28 years. Forty-eight participants were white, while two were non-white. The maximum gravidity was 6 , while the maximum parity was 5 . Thirty-two subjects were multiparous, and seventeen were primiparous. All but one subject were married.

The obstetrical care at this hospital is traditional care; that is, care is given to mother and baby by two 
separate staffs, and visiting hours are regulated. Consent was obtained at the time of administration of the first questionnaire. Ethical considerations taken into account were those of privacy and confidentiality, which were maintained. Permission to implement the study was obtained from the hospital and the attending obstetricians. 


\section{RESULTS}

All analysis was done on the two total scale scores: that is, the sum of the thirteen "taking-in" items and the sum of the nine "taking-hold" items. Martell and Mitchell (1984) assigned one point for each behavior, that is, it was possible to achieve a maximum of 13 for "taking-in" and a maximum of 9 for "taking-hold". In this study a maximum total of 52 was possible for "taking-in" and a maximum of 36 was possible for "taking-hold" scores. On the revised scale, the mean "taking-in" score at time one was 33.7 $(+/-4.77)$ and at time five was $28.4(+/-4.08)$. The mean "taking-hold" score at time one was $22.7(+/-2.76)$ and was $27.6(+/-2.40)$ at time five. This shows a decreasing pattern of "taking-in" and an increasing pattern of "taking-hold".

When reliability studies were performed on the scales, the results were mixed. Internal consistency reliability (coefficient alpha) was fairly good at all times on the "taking-in" scale $(\mathrm{T} 1=.63, \mathrm{~T} 2=.61, \mathrm{~T} 3=.60, \mathrm{~T} 4=.68$, T5=.67). Internal consistency reliability scores for "taking-hold" were marginal $(\mathrm{T} 1=.30, \mathrm{~T} 2=.53, \mathrm{~T} 3=.43, \mathrm{~T} 4=.43$, 
T5 =.46). Therefore, data related to "taking-hold" must be interpreted with caution (see discussion).

Data were analyzed using a repeated measures analysis of variance (ANOVA). Questionnaire scores were first examined to see if women showed decreasing "taking-in" scores and increasing "taking-hold" scores. The change was significant for "taking-in" scores as they declined progressively over time $(\underline{F}=47.01, \underline{\text { df } 1=4, ~} \underline{\text { dff }} 2=49, p<.001)$. Conversely, "taking-hold" scores increased significantly over time $(\underline{F}=61.40, \underline{d f} 1=4, \underline{d f} 2=49, p<.001)$ (see Table 1). Tukey's post hoc tests were performed for both the variables of "taking-in" and "taking-hold" over time. "Taking-in" scores showed no significant change between Time 1, Time 2, or Time 3. "Taking-in" scores did decrease significantly between Time 3 and Time 4 , and between Time 4 and Time 5 (from bedtime on). "Taking-hold" scores also showed no significant change between Time 1, Time 2, or Time 3 , but did increase significantly between Time 3 and Time 4 and betwen Time 4 and Time 5 (from bedtime on).

Scale scores were converted to $z$-scores and then "taking-in" scores were plotted with the "taking-hold" scores. It is evident that the changes in the behaviors in question occur on the first postpartum day (see Figure 1). 
Table 1

Results of Repeated measures ANOVA for all participants

\begin{tabular}{|c|c|c|c|c|c|c|c|c|c|c|}
\hline & I & & TAKING IN & & & & & TAKING H & OLD & \\
\hline SOURCE & ss & DF & MS & $\mathbf{F}$ & $\mathbf{P}$ & SS & DF & MS & $\mathbf{F}$ & \\
\hline BLOCKS/SUBJECTS & I 3539.124 & 49 & & & & 1088.99 & 49 & & & \\
\hline & I & & & & & & & & & \\
\hline TAKING & I 998.264 & & 249.566 & 47.008 & $<.001$ & 921.49 & & 230.374 & 61.400 & $<.0011$ \\
\hline ERROR & I 1040.536 & 196 & 5.309 & & & 735.30 & 196 & 3.752 & & \\
\hline
\end{tabular}




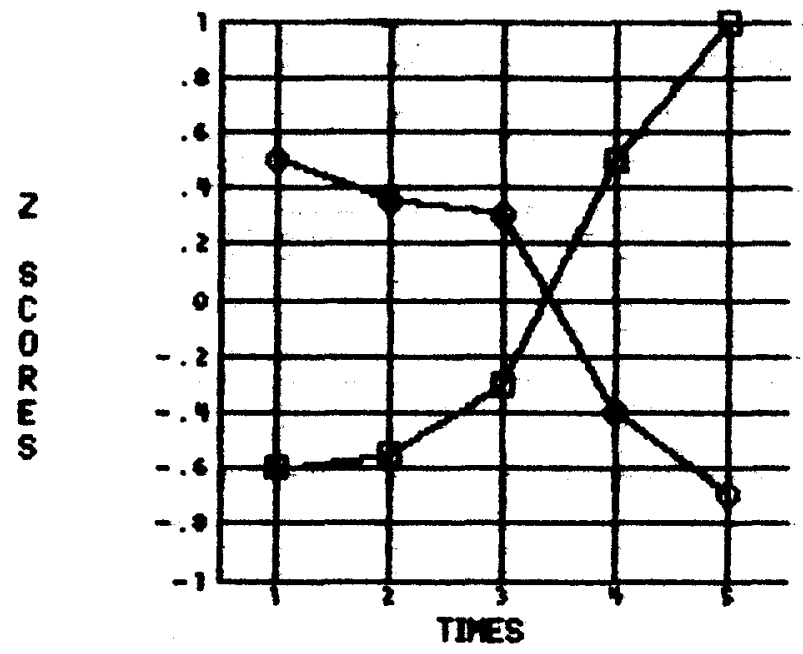

Figure 1. "Taking-in" scores in relation to "taking-hold" scores. (Scores have been standardized; $0=$ taking-in and []=taking-hold). 
Subjects were then divided further into groups by ages and parity. Age was divided at 28 years, since that was the median. Nineteen subjects were over 28 , and thirty-one were 28 or under. Thirty-two subjects were of parity greater than one, while seventeen were primiparas. The changes over time for both groups were significant for "taking-in" and "taking-hold" (see Table $2 \& 3$ ).

Those women 28 or younger had higher scores for both "taking-in" and "taking-hold", but by time 5 on the "taking-hold" scale both scores merged (see Figures 2 \& 3 ). For primiparas the "taking-in" scores were higher than those of multiparas. The "taking-hold" scores were very similar, though, for both parity groups and both age groups (see Figure $4 \& 5)$. 
Table 2

Results of repeated Measures ANOVA by Parity

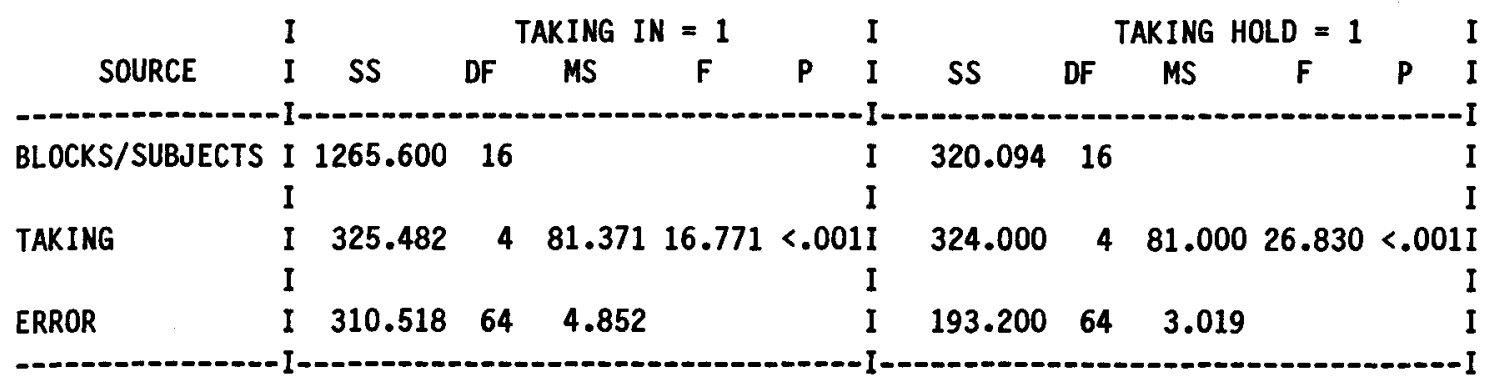

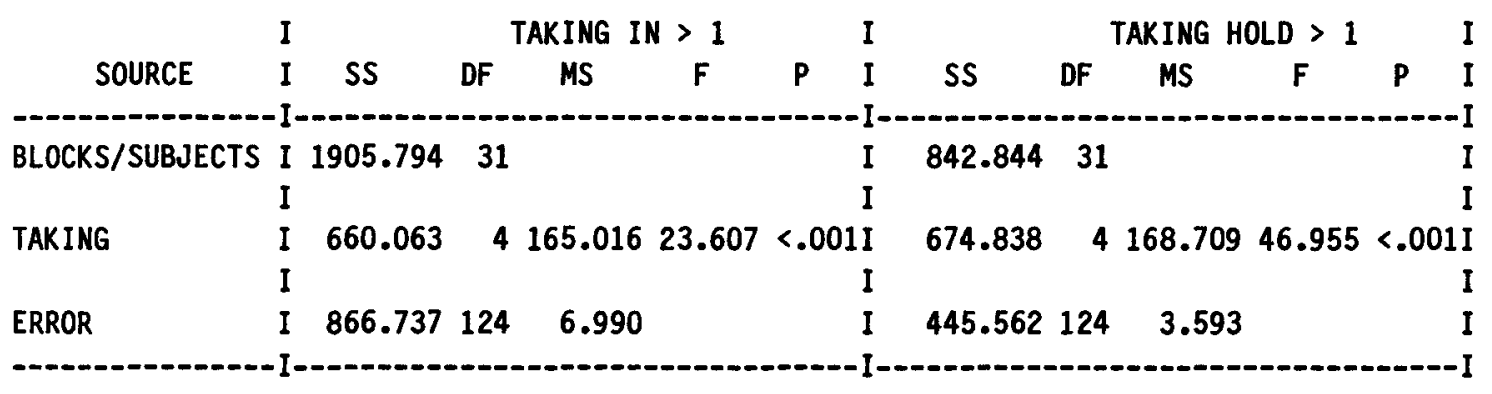


Table 3

Results of Repeated Measure ANOVA by Age

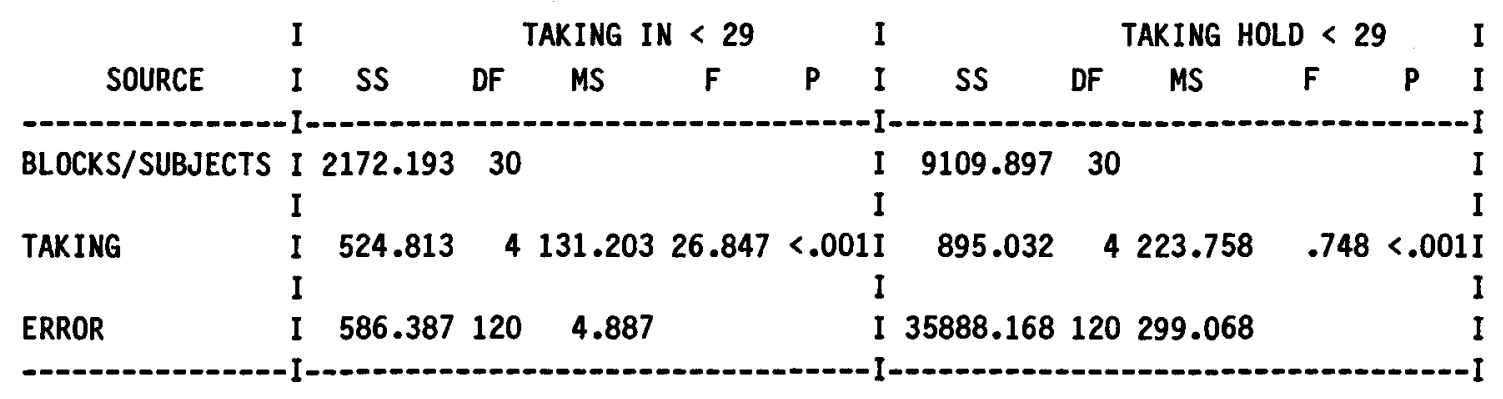

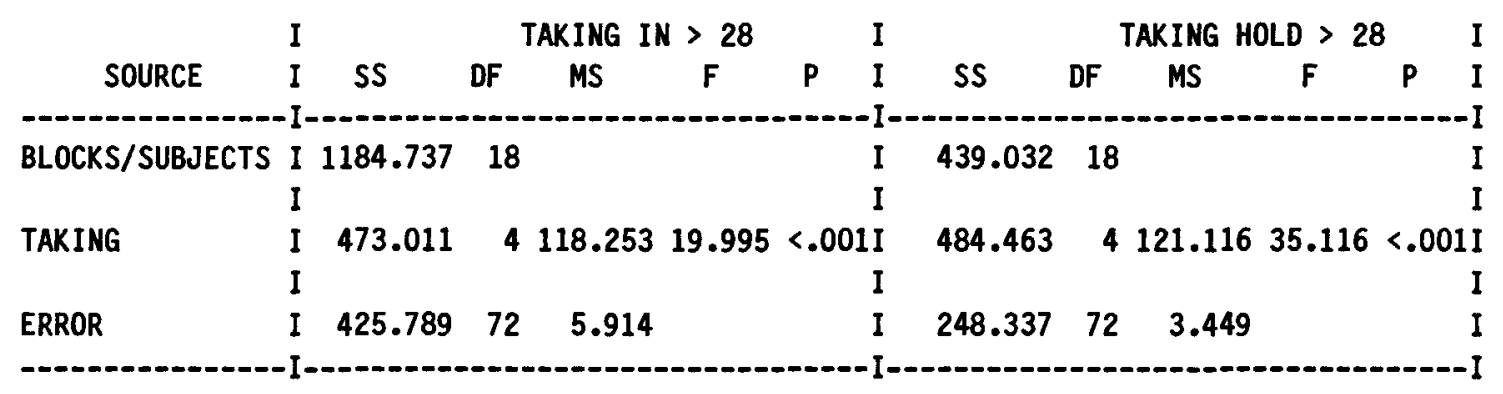




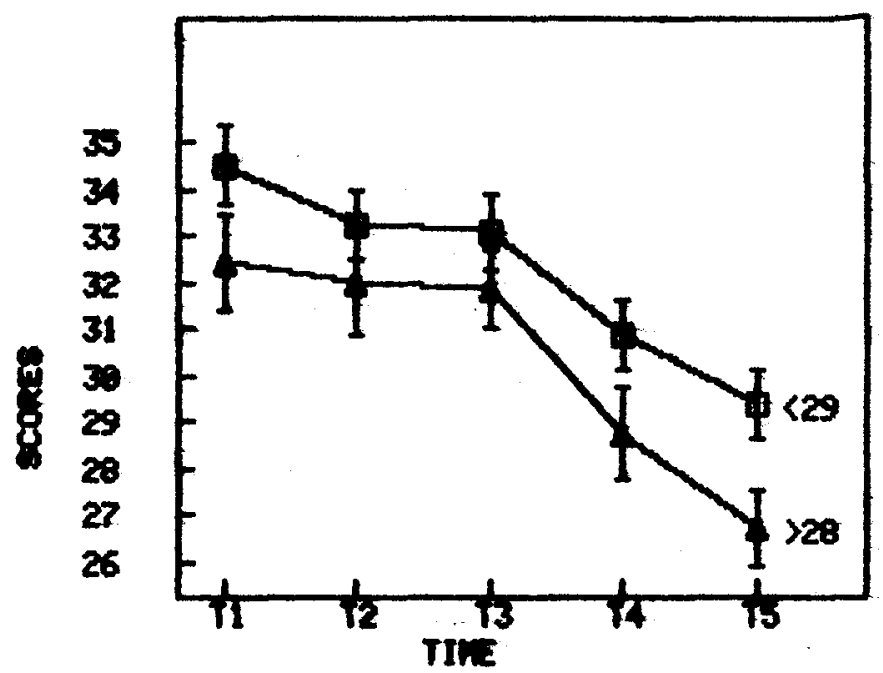

Figure 2. "Taking-in" scores by age groups over time. 


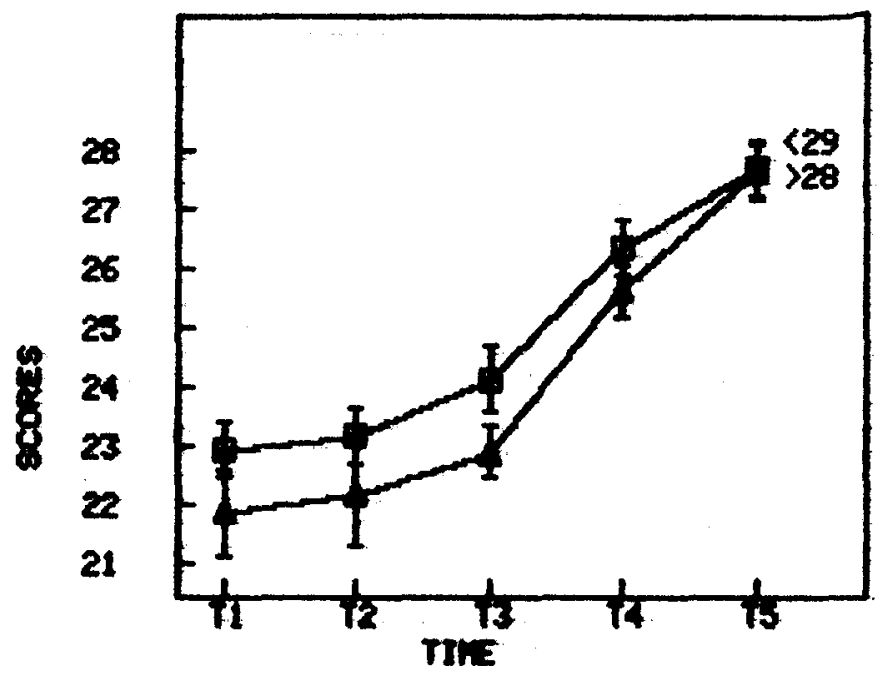

Figure 3. "Taking-hold" scores by age groups over time. 


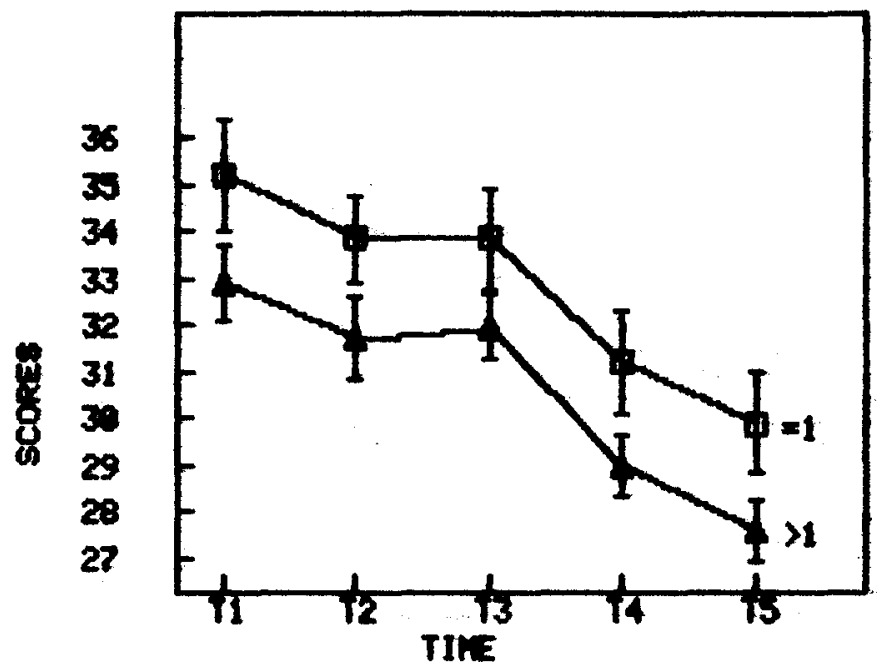

Figure 4. "Taking-in" scores by parity over time. 


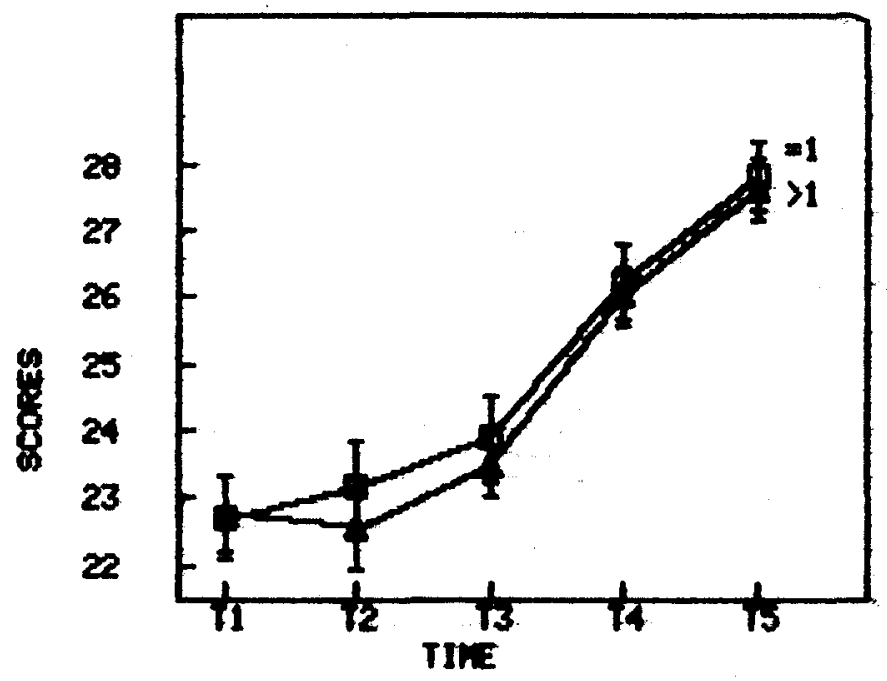

Figure 5. "Taking-hold" scores by parity over time. 


\section{CHAPTER 5}

\section{DISCUSSION}

Fifty postpartal women were given a self-administered questionnaire at five time intervals during their three-day hospital stays. "Taking-in" scores declined progressively and significantly over time $(\underline{F}=47.01, \underline{\text { df }} 1=4, \underline{\text { df }} 2=49$, $\mathrm{p}<.001)$. Conversely, "taking-hold" scores increased significantly over time $(\underline{F}=61.40, \underline{d f} 1=4, \underline{d f} 2=49, p<.001)$. There was evidence for an early "taking-in" period. These behaviors differ from Rubin's (1961) original descriptions in reference to time. This data supports a change occurring by the parturient's first day, between bedtime on the day of delivery and the first postpartum morning.

The behaviors and attitudes in question do change over time during the course of hospitalization. There is evidence for significant changes in both phases, and the data is supportive of Rubin's (1961) classic work. Thus Rubin's theory of the concepts and their change over time has not been altered, but the time frames in which they occur have changed. Rubin (1984) determined that the "taking-in" phase persisted for two to three days; in this 
study, a strong "taking-in" phase was only noted in the first twenty-four hours postpartum.

\section{Limitations and Needs for Future Research}

Limitations as to the reliability and validity of Martell \& Mitchell's (1984) questionnaire still exist. Have the questions successfully measured the concepts? As shown by internal consistency reliability scores, scale problems exist. "Taking-in" has been adequately measured, but "taking-hold" has only been marginally measured. The instrument needs to be examined more closely. If further research on the concepts is to be done, a better instrument for measurement needs to be developed.

There are many questions for future research that have arisen from this study. Do age and parity greatly influence the amount of "taking-in" and "taking-hold" one does? Slight differences by age and parity were observed in this study; however, tests for significance were not done. This study involved a largely white, middle-class, married population. Would the results be similar if different socioeconomic or ethnic groups were studied? This study also focused on uncomplicated vaginal deliveries. Would "taking-in" and "taking-hold" behaviors progress similarly among a high-risk population? What if the woman delivered 
by Cesarean section? Would the behaviors evolve if the parturient had no identifiable support system?

Many variables alter the woman's perception of her labor and delivery experience, which can affect achievement of maternal tasks. These were not taken into consideration for this study. The average length of labor and medications administered during labor were not considered. All women participating delivered healthy infants. Would the scores for "taking-in" and "taking-hold" be different if the infant was premature, ill, handicapped, or malformed?

This study has not considered changes in nursing and obstetrical practices which have occurred since Rubin's (1961) original work; for example, the increased technology available for maternity care. Discrepancies in results may have occurred due to changed medical practice, social attitudes and norms, client education, and much more. What may need to be examined first is the influence of time over childbearing attitudes.

\section{Implications for Practice}

What implications do these results have for nursing practice? Postpartal women are encouraged to be independent on their first day. Taking into consideration these results, women are not ready to absorb the vast amount of information presented to them. They should not be expected 
to learn and perform return demonstrations with their infants until twenty-four hours postpartum. Instead, they should be encouraged to verbalize the experience of their labor and delivery.

Due to the increasing influence of economics over health care, women are being discharged on the first or second postpartum day. They are forced to become independent rapidly. When the tasks of "taking-in" do not decline until twenty-four hours postpartum, independence may be an unrealistic expectation. On the other hand, women anticipating early discharge may complete the tasks at a faster pace. Further research is needed to clarify the effects of early discharge. In the meantime, nurses need to assist all women to "take-in" and, subsequently, "take-hold". 
Avery, M.D., \& Fournier, I.C. (1982). An early postpartum discharge program. JOGN Nursing, 11, 233-235

Bul1, M.J. (1981). Change in concerns of first-time mothers after one week at home. JOGN Nursing. 10, 390-394.

Carr, K.C., \& Walton, V.E. (1982). Early postpartum discharge. JOGN Nursing. 11, 29-30.

Clausen, J.P., Flook, M.H., \& Ford, B. (1977) . Maternity nursing today (2nd ed.). New York: McGraw Hill.

Haller, K.B., Reynolds, M.A., \& Horsley, J.A. (1979) . Developing research-based innovation protocols: Process, criteria, and issues. Research in Nursing and Health, $\underline{2}, 45-51$.

Jones, D. (1978) . Home early after discharge. American Journal of nursing, 78, 1378-1380.

Maloni, J.A., \& Stegman, C.E. (1984). More puerperal change \{letter to the editor\}. JOGN Nursing, 13, 145-149.

Martell, L.K., \& Mitchell, S.K. (1984). Rubin's "puerperal change" reconsidered. JOGN Nursing, 13, 145-149.

Mercer, R.T. (1981). The nurse and maternal tasks of early postpartum. $\underline{\mathrm{MCN}}, \underline{6}, 341-345$.

Polit, D.F., \& Hungler, B.P. (1983). Nursing research: Principles and methods (2cd ed) - Fhiladelphia: Lippincott.

Reeder, S., Mastroianni, L., \& Martin, L. (1983) . Maternity Nursing. J.B. Lippincott Company: Philadelphia.

Rubin, R. (1961). Puerperal change. Nursing Outlook, $\underline{9}$ $(12), 743-755$.

Rubin, R. (1967). Attainment of the maternal role. Nursing Research, 16, (3), 237-245.

Rubin, R. (1984). Maternal identity and the maternal experience. New York: Springer.

Sasmor, J.L., \& Grossman, E. (1981). Childbirth education in 1980. JOGN Nursing, 10, 155-160.

Ziegel, E., \& VanBlarcom, C.C. (1972). Obstetric nursing $(6$ th ed, ). New York: MacMillan. 
APPENDIX A 


\section{DURATION AND BEHAVIORS OF CONCEPTS}

(Rubin, 1961)

A. "Taking-in"

1. Duration: two to three days

2. Behaviors: sleep

food consumption

talkative

concern for baby's oral intake assimilation of delivery experience passive and dependent

B. "Taking-hold"

1. Duration: three to ten days

2. Behaviors: focus on present

intolerant of delays

involvement in internal body functioning mood swings

concern for others

vulnerable

autonomy and independence 
POSTPARTUM QUESTIONNAIRE

$\mathrm{SA}=$ strongly agree $\mathrm{A}=$ agree $\mathrm{D}=$ disagree $\mathrm{SD}=$ strongly disagree

* 1. I cannot stand delays today..............

* 2. Today I am making plans to go home.........

3. I am really tired today .................

4. I want to understand more about

my 1 abor and delivery ...................

5. I feel high (euphoric)................

* 6. I have more energy today than yesterday....

7. The nurses have to tell me to do things

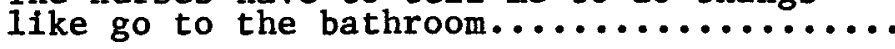

8. I want to sleep alot..................

9. What is going on with me is

my main interest.......................

10. I cannot seem to get enough to eat.........

11. I have food saved for later in this room...

* 12. I want to have visitors.................

* 13. I am speaking up (asserting myself)

to get the things $I$ want...................

* 14. I have been organizing my things today.....

15. I cannot quite believe I had the baby......

* 16. I want to be up and about................

17. I want to be the center of attention.......

* 18. I am anxious to learn al1 I can about

taking care of my baby...................

19. I try to do what people ask me to do.......

* 20. I am concerned about the people at home....

21. I do not feel active today..............

22. I want people to do things for me.........

* These items make up "taking-hold" 1tems. The rest are "taking-in"

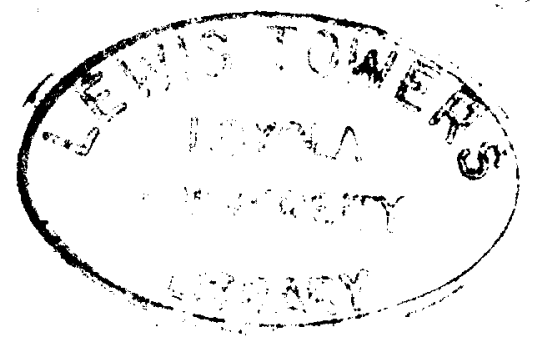




\section{DEMOGRAPHIC DATA}

1. Medical Records Number

2. Age

3. Gravidity

4. Parity

5. Ethnicity

6. Marital Status

7. Socioeconomic Status 
APPENDIX B 

Date:

Project Title: Maternal Tasks of the Puerperium Reidentified Client Information:

We are conducting a study to learn more about a mother's recovery after childbirth, and we are asking you to participate in this study. By participating in this study you will help nurses increase our understanding of the recovery period and thus enable us to improve the nursing care we give to future mothers after childbirth.

Participation in this study will involve completing a one-page questionnaire consisting of 22 statements requiring an agree or disagree answer at various times during your hospital stay, for a total of five. All nurses involved in this study are employed at Lake Forest Hospital; and the principal investigator is Lynette Ament, RN, BSN, who is a graduate student at Loyola University of Chicago.

There are no anticipated risks involved for you if you choose to participate in this study. There are no direct benefits to you from participation in this study. Your name will not be associated with the final results. The alternative is non-participation in this study, which will not prejudice your care.

I have fully explained to the nature and purpose of the above described research and the risks that are involved in its performance. I have answered and will answer all questions to the best of my ability.

\section{Principal Investigator or Research Associate}

I have been fully informed of the above described procedure with its possible risks and benefits. I give permission for my participation in this study. I know that Lynette Ament will be available to answer any questions that I may have. I understand that I am free to withdraw this consent and discontinue my participation in this study at any time without prejudice to my medical care. I have received a copy of this informed consent document.

I agree to allow my name and research records to be avallable to other authorized physicians, nurses, and researchers for the purpose of evaluating the results of this study. I consent to the publication of any data which may result from these investigations for the purpose of advancing medical and/or nursing knowledge, providing my name or any other identifying information (initials, social security numbers, etc.) is not used in conjunction with such publication. All precautions to maintain confidentiality of the medical records will be taken. I understand, however, that the Food and Drug Administration of the United States Government is authorized to review the records relating to this project.

\section{Client}

Witness to Signatures 


\section{AFPROVAL SHEET}

The thesis submitted by Lynette A. Ament has been read and approved by the following committee:

Dr. Karen Haller, Director

Associate Professor, Nursing, Loyola

Dr. Dona Snyder

Associate Professor, Nursing, Loyola

Ms. Marcia Maurer

Assistant Professor, Nursing, Loyola

The final copies have been examined by the director of the thesis and the signature which appears below verifies the fact that any necessary changes have been incorporated and that the thesis is now given final approval by the committee with reference to content and form.

The thesis is therefore accepted in partial fulfillment of the requirements for the degree of Master of Science in Nursing.
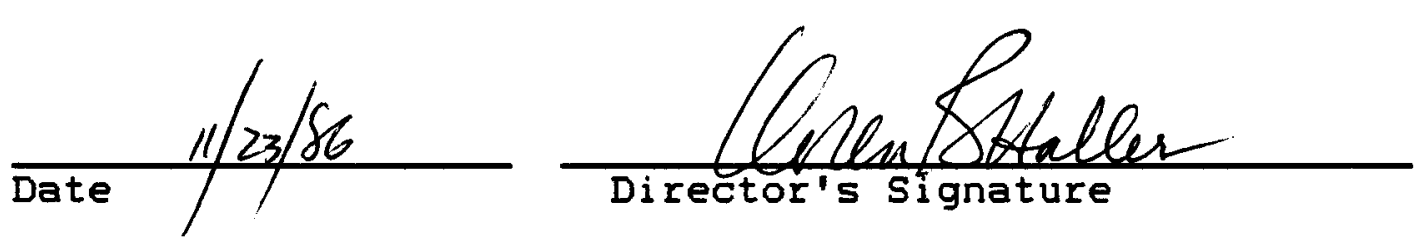

Director's signature 